\title{
Induction of labour at term: 25 mcg 2 hourly oral misoprostol or 6 hourly intracervical cerviprime, safety and efficacy
}

\author{
Indrani Mukhopadhyay*, Dishant Sisodia
}

Department of Obstetrics and Gynecology, 7 Air Force Hospital, Kanpur, Uttar Pradesh, India

Received: 21 October 2019

Revised: 19 November 2019

Accepted: 28 November 2019

\section{*Correspondence:}

Dr. Indrani Mukhopadhyay,

E-mail: indrani.mukho@gmail.com

Copyright: () the author(s), publisher and licensee Medip Academy. This is an open-access article distributed under the terms of the Creative Commons Attribution Non-Commercial License, which permits unrestricted non-commercial use, distribution, and reproduction in any medium, provided the original work is properly cited.

\section{ABSTRACT}

Background: There are various methods for induction of labour, both mechanical and pharmacological. Prostaglandins in induction have been commonly used. Studies have been done using vaginal and sublingual use of misoprostol. This study analyses efficacy of both oral misoprostol used in low frequent doses as per FIGO 2017 guidelines and intracervical prostaglandins for induction of labour.

Methods: A total 159 consecutive pregnant term mothers with singleton pregnancy, intact membranes and unfavorable cervix were subdivided into two subgroups, first subgroup was administered 25 mcg oral misoprostol at 2 hourly interval and those in subgroup B were given intracervical PGE2. Both these subgroups were prospectively followed to assess efficacy in induction of labour at term and outcome in foetus and mother. Statistical analysis was done using chi square test.

Results: It was found that the induction to delivery interval was significantly lesser in the cerviprime group (19.31 hours) compared to the misoprostol group (25.19 hours). However, there was no significant difference in the rate of vaginal delivery and mean duration of labour, rates of caesarean section, maternal and neonatal complications in both the groups. More women in the cerviprime group required augmentation with oxytocin. However, on comparing the cost of induction as per the mean doses used, the cost of induction with misoprostol was much lesser than that of cerviprime use.

Conclusions: Oral use of Tab. misoprostol was not more efficacious than the use of cerviprime gel in induction of labour.

Keywords: Comparative study, Cerviprime, Induction of labour, Misoprostol

\section{INTRODUCTION}

Cervical ripening has been a part of induction of labour. The process of cervical ripening also results in the induction of labour in many cases. Induction of labour has been defined as the process to artificially initiate labour in the mother that leads to the delivery of the fetus. Induction of labour occurs in up to $35 \%$ of pregnancies and mostly applied in cases where there the mother or the fetus is at high risk due to problems such as hypertension or diabetes or problems in the foetus such as foetal growth restriction, macrosomia, postdatism. ${ }^{1,2}$

A number of pharmacological and non-pharmacological methods are used for Induction of labour. Pharmacological methods include use of oxytocin and prostaglandin (PG) analogues, whereas nonpharmacological methods include mechanical methods such as stretching of the cervix digitally and sweeping of the membranes, artificial rupture of the membranes, use 
of hygroscopic cervical dilators, balloon catheters like Folleys catheter. ${ }^{3}$ Prostaglandins have been routinely used for years for cervical ripening and induction of labour. The commonly used prostaglandins in our practise are PGE1 (misoprostol) and PGE2 (cerviprime).

Misoprostol, a prostaglandin E1 analogue, has been used to inhibit gastric secretion for prevention of gastric ulcers. After approval of FDA for its off label use, due to its uterotonic effect throughout pregnancy, it has been used effectively to induce abortions and labour. Misoprostol has several advantages compared with other prostaglandins as it is cheap, stable at room temperature, can be administered orally or vaginally, is rapidly absorbed even orally forming its metabolically active product misoprostol acid within 30 minutes. Misoprostol has positive effects on cervical ripening due to its effects on collagenases apart from inducing uterine contractions. It is available in doses of 25, 50, 100, 200, 600 microgram. The most common adverse effects of misoprostol are nausea, vomiting, diarrhoea, abdominal pain, chills, shivering, and fever, all of which are dosedependent. ${ }^{3}$ Although other prostaglandins (prostaglandin E2 and prostaglandin F2a) can cause myocardial infarction and bronchospasm, misoprostol does not.6 Toxic doses of misoprostol have not been ascertained however, cumulative doses going up to $2200 \mu \mathrm{g}$ administered over a period of 12 hours have been tolerated by pregnant women. ${ }^{4}$

Cerviprime (PGE2), is available in the form of gel in a prefilled $2.5 \mathrm{ml}$ syringe in a $0.5 \mathrm{mg}$ dose and the gel is instilled intra-cervically.

In 2012, the FIGO produced guidelines for the prevention and treatment of $\mathrm{PPH}$ with misoprostol with recommended dosages of misoprostol when used alone for a variety of gynecological and obstetric indications. In June 2017, FIGO released an updated chart outlining the recommendations for dosages and routes of administration for misoprostol. This chart recommends the use of oral misoprostol in the dose of $25 \mathrm{mcg}$ orally every 2 hours. ${ }^{5}$

Clinical study was conducted to compare the efficacy and safety of low dose of oral 25 microgram misoprostol in controlled dosing, repeated at intervals of 2 hours as per the FIGO guidelines of 2017 with that of cerviprime gel containing $0.5 \mathrm{mg}$ PGE2 in cervical ripening and labour without any previous rupture of membranes. Also, it was done to study which form of induction was better with respect to patient compliance, in the prevention of the complications such as uterine tachysystole or foetal distress and meconium staining.

\section{METHODS}

This prospective study was done at the hospital in Kanpur over 15 months starting from July 18 to September 19 . 159 women admitted for induction of labour in the hospital were randomly selected for study, 82 women received 25 microgram oral misoprostol and another 77 women $0.5 \mathrm{mg}$ of intracervical dinoprostone gel. A written informed consent was taken from the patients. Five women did not give consent for the study.

\section{Inclusion criteria}

- The women were those with singleton pregnancy, cephalic presentation, >36 completed weeks gestation confirmed by ultrasonography and proper dating with no fetal heart rate abnormalities and with a Bishop s score $<5$.

\section{Exclusion criteria}

- Those women with multiple pregnancies, pregnancy $<36$ weeks, previous caesarean section abnormal presentation, intrauterine fetal demise, previous rupture of membranes, cervix $\geq 3$ centimetre dilatation, hypersensitivity to prostaglandins, history of any uterine surgery like myomectomy or hysterotomy, placenta praevia, meconium stained liquor were excluded.

Group I: Patients who received misoprostol for induction of labour.

Group II: Patients who received cerviprime gel for induction of labour.

Primary outcome was to compare the induction to delivery interval.

The secondary outcome measured was the need for oxytocin augmentation, failed induction (failure of the cervix to dilate and failure to initiate uterine contractions), mode of delivery, rate of caesarean sections, meconium stained liquor, occurrence of tachysystole, any other maternal or foetal complications.

Labour was charted following the WHO partogram and managed according to labour room protocol. The progress of labour was decided by uterine contractions and per vaginal examination for cervical dilatation. Tab. misoprostol 25 microgram was repeated orally at 2 hrly intervals till the presence of 3 uterine contractions over 10 minutes. The maximum dose of tab misoprostol given was 24 doses ( 48 hours) beyond which it was termed as failed induction if active phase was not reached and a caesarean section done. Cerviprime gel was instilled intra-cervically every 6 hours till a maximum of 3 doses or decided as per entry into active phase of labour. The active phase was defined as per WHO criteria as when there was cervical dilatation of at least $4 \mathrm{~cm}$. Labour was augmented depending on uterine contractility, and oxytocin used. No augmentation was done when uterine contractions reached a frequency of 3 in 10 minutes. Abnormal uterine activity in the form of uterine tachysystole, more than five contractions in 10 mins of 60 
seconds were noted. Induction was considered successful with the drug of induction if labour entered into active phase within 24 hours of the initial administration of the drug. The results were calculated as mean and standard deviation. Chi square tests were applied to know the statistical significance. Qualitative variables were expressed as percentages.

\section{RESULTS}

Table 1: Parity of women in the study.

\begin{tabular}{|lll|}
\hline Parity & Frequency & Percentage \\
\hline Primigravida & 50 & 31.45 \\
\hline Multigravida & 109 & 68.55 \\
\hline Total & $\mathbf{1 5 9}$ & $\mathbf{1 0 0}$ \\
\hline
\end{tabular}

A total of 159 gravid women were included in this study. Out of 159 women 77 women received cerviprime gel for induction of labour and 82 women received oral misoprostol. In this study the larger percentage (68.55\%) of the study population were multigravidae compared to primigravidae $(31.45 \%)$ (Table 1$)$.

Also, in the study the mean gestational age in those ladies who received cerviprime was 40 weeks 03 days as compared to the misoprostol group whose mean gestational age was 39 weeks 06 days and hence the two groups were comparable (Table 2).

The commonest indication for induction in both groups was postdatism, $71.05 \%$ in the cerviprime group and 51.225 in the misoprostol group. The next commonest indication in the cerviprime group was oligohydramnios $(9.21 \%)$ and third gestational diabetes mellitus (7.89\%). In the misoprostol group the second commonest indication was pregnancy induced hypertension (17.07\%) and the third was intrahepatic cholestasis of pregnancy $(14.63 \%)$ (Table 3).

Table 2: Mean gestational age of women studied.

\begin{tabular}{|llllll|}
\hline & \multicolumn{2}{l}{ Cerviprime group } & \multicolumn{4}{l|}{ Misoprostol group } & \\
\hline & Mean & SD & Mean & SD & p-value \\
\hline $\mathrm{N}$ & 77 & & 82 & & \\
\hline Period of gestation in weeks & 40.03 & 0.93 & 39.60 & 1.12 & $<0.01$ \\
\hline
\end{tabular}

Table 3: Indications for elective induction.

\begin{tabular}{|lllll|}
\hline & \multicolumn{2}{l|}{ Cerviprime group } & \multicolumn{2}{c|}{ Misoprostol group } \\
\hline Indication for induction & Frequency & Percent & Frequency & Percent \\
\hline Decreased fetal movements & 2 & 2.63 & 3 & 3.66 \\
\hline FGR & 1 & 1.32 & 2 & 2.44 \\
\hline GDM & 6 & 7.89 & 5 & 6.1 \\
\hline ICP & 4 & 5.26 & 12 & 14.63 \\
\hline Oligohydramnios & 7 & 9.21 & 4 & 4.88 \\
\hline PIH & 2 & 2.63 & 14 & 17.07 \\
\hline Postdatism & 54 & 71.05 & 42 & 51.22 \\
\hline Total & $\mathbf{7 6}$ & $\mathbf{1 0 0}$ & $\mathbf{8 2}$ & $\mathbf{1 0 0}$ \\
\hline
\end{tabular}

Table 4: Induction to delivery intervals.

\begin{tabular}{|c|c|c|c|c|c|}
\hline & \multicolumn{2}{|c|}{ Cerviprime group } & \multicolumn{2}{|c|}{ Misoprostol group } & \multirow[b]{2}{*}{ p-value } \\
\hline & Mean & SD & Mean & SD & \\
\hline $\mathrm{N}$ & 76 & & 79 & & \\
\hline Induction to active phase in hours & 11.53 & 7.08 & 16.46 & 9.33 & $<0.01$ \\
\hline Active to delivery in hours & 6.38 & 2.05 & 6.61 & 2.06 & $<0.05$ \\
\hline Induction to delivery in hours & 19.31 & 10.30 & 25.19 & 11.04 & $<0.01$ \\
\hline
\end{tabular}

In the comparison of induction to delivery in both groups it was found that the induction to delivery time in the cerviprime group was less (11 hours 53 mins versus 16 hours 46 mins) than that in the misoprostol group and the result was statistically significant. Also, the time taken from the active phase to delivery in the cerviprime group was lesser (6 hours 38 mins versus 6 hours 61 mins) and that was also significant. Hence the overall induction to delivery interval was lesser in the cerviprime group (19 hours 31 mins versus 25 hours 19 mins) as compared to the misoprostol group and it also proved to be statistically significant (Table 4). 
It is seen that the mean duration of labour among the primis with the use of cerviprime versus misoprostol was 8.27 hours versus 8.13 hours respectively but that was not statistically significant. Similarly, among the multis the mean duration of labour between the cerviprime and the misoprostol groups was also not significant (Table 5).

Table 5: Mean labour duration.

\begin{tabular}{|c|c|c|c|c|c|c|c|c|c|c|}
\hline & \multicolumn{5}{|l|}{ Primi } & \multicolumn{5}{|l|}{ Multi } \\
\hline & \multicolumn{2}{|c|}{ Cerviprime group } & \multicolumn{3}{|c|}{ Misoprostol group } & \multicolumn{2}{|c|}{ Cerviprime group } & \multicolumn{3}{|c|}{ Misoprostol group } \\
\hline & Mean & SD & Mean & SD & p-value & Mean & SD & Mean & SD & p-value \\
\hline $\mathrm{N}$ & 44 & & 62 & & & 32 & & 17 & & \\
\hline $\begin{array}{l}\text { Total duration } \\
\text { in minutes }\end{array}$ & 472.07 & 217.20 & 463.82 & 128.39 & $>0.05$ & 359.28 & 159.66 & 431.24 & 164.08 & $>0.05$ \\
\hline $\begin{array}{l}\text { Total duration } \\
\text { in hours }\end{array}$ & 8.27 & 3.62 & 8.13 & 2.14 & $>0.05$ & 5.99 & 2.66 & 7.19 & 2.73 & $>0.05$ \\
\hline
\end{tabular}

Table 6: Total number of doses.

\begin{tabular}{|c|c|c|c|c|c|c|c|c|}
\hline & Primi & & & & Multi & & & \\
\hline & Cervip & cime group & Misop & group & Cervip & group & Misop & sroup \\
\hline & Mean & SD & Mean & SD & Mean & SD & Mean & SD \\
\hline $\mathrm{N}$ & 45 & & 64 & & 32 & & 18 & \\
\hline No. of doses & 2.16 & 1.46 & 10.17 & 5.54 & 1.47 & 0.72 & 7.50 & 5.40 \\
\hline
\end{tabular}

The total number of doses required amounted to 2.16 mean doses of cerviprime in primis, amounting to around Rs 547.56 (Rs 253.50 per dose) as compared to mean dose of 10.17 with misoprostol amounting to Rs 63.56 (Rs 25 per 04 tablets). In multis the mean dose of cerviprime was 1.47 (Rs 372.64) versus mean dose of 7.50 (Rs 46.87) in the misoprostol group. Hence the cost of induction with misoprostol was much cheaper than using cerviprime gel inspite of lesser number of doses in the cerviprime group (Table 6).

The study showed that in both the groups oxytocin augmentation was required, $53.85 \%$ in the cerviprime group and $46.17 \%$ in the misoprostol group as seen in Table 7.
Table 7: Oxytocin augmentation.

\begin{tabular}{|lll|}
\hline Augmentation with oxytocin & Frequency & Percent \\
\hline Cerviprime group & 14 & 53.85 \\
\hline Misoprostol group & 12 & 46.15 \\
\hline Total & $\mathbf{2 6}$ & $\mathbf{1 0 0}$ \\
\hline
\end{tabular}

It was seen that most of the women in both the groups (92.10\% cerviprime versus $87.95 \%$ misoprostol) had a vaginal delivery and this was not statistically significant. Instrumental deliveries were noted more in the misoprostol group. However, the caesarean sections done in both the groups were not statistically significant (7.89\% cerviprime versus $4.81 \%$ misoprostol) (Table 8 ).

Table 8: Mode of delivery.

\begin{tabular}{|llllll|}
\hline & \multicolumn{2}{l|}{ Cerviprime group } & \multicolumn{2}{c|}{ Misoprostol group } \\
\hline Mode of delivery & Frequency & Percent & Frequency & Percent & p-value \\
\hline FTND & 70 & 92.10 & 73 & 87.95 & $>0.05$ \\
\hline Instrumental & 0 & 0 & 6 & 7.22 & $<0.05$ \\
\hline LSCS & 6 & 7.89 & 4 & 4.81 & $>0.05$ \\
\hline Total & $\mathbf{7 6}$ & $\mathbf{1 0 0}$ & $\mathbf{8 3}$ & $\mathbf{1 0 0}$ & \\
\hline
\end{tabular}

The primary indication for caesarean in the misoprostol group was failed indication $(75 \%)$ whereas the main indication in the cerviprime group was fetal distress $(66.66 \%)$. The other indication in the misoprostol group was fetal distress $(25 \%)$ lesser than the cerviprime group. In the cerviprime group the indications were failed induction and meconium stained liquor (16.66\%) each (Table 9). 
Table 9: Indication for caesarean.

\begin{tabular}{|lll|}
\hline $\begin{array}{l}\text { Indication for } \\
\text { caesarean }\end{array}$ & $\begin{array}{l}\text { Misoprostol } \\
\text { group }\end{array}$ & $\begin{array}{l}\text { Cerviprime } \\
\text { group }\end{array}$ \\
\hline Fetal distress & $1(25 \%)$ & $4(66.66 \%)$ \\
\hline Failed induction & $3(75 \%)$ & $1(16.66 \%)$ \\
\hline MSL & 0 & $1(16.66 \%)$ \\
\hline
\end{tabular}

The main complaints of women with intake of misoprostol were GI symptoms (3.69\%) like abdominal pain with diarrhoea associated with nausea and vomiting $(3.65 \%)$. Fever was recorded only in two patients $(2.43 \%)$ with misoprostol use and only one patient had uterine tachysystole $(1.29 \%)$ during labour managed with terbutaline. In the cerviprime group, most of the patients developed GI symptoms (Table 10).

Table 10: Maternal complications.

\begin{tabular}{|lll|}
\hline Maternal side effects & Misoprostol group $(\mathbf{N})$ & Cerviprime group (N) \\
\hline Nausea, vomiting & $3(3.65 \%)$ & $1(1.29 \%)$ \\
\hline Fever with chills & $2(2.43 \%)$ & - \\
\hline GI symptoms & $3(3.65 \%)$ & $2(2.59 \%)$ \\
\hline Uterine tachysystole & $1(1.21 \%)$ & - \\
\hline Vaginal lacerations & - & - \\
\hline Precipitate labour & - & - \\
\hline
\end{tabular}

Table 11: Neonatal complications.

\begin{tabular}{|lllll|}
\hline Neonate & Cerviprime group & \multicolumn{2}{l|}{ Misoprostol group } \\
\hline & Frequency & Percent & Frequency & Percent \\
\hline Severe birth asphyxia with NICU admission & 0 & 0 & 1 & 100 \\
\hline Low APGAR $(<7$ in 05 mins) & 4 & 100 & 0 & 0 \\
\hline Total & $\mathbf{4}$ & $\mathbf{1 0 0}$ & $\mathbf{1}$ & $\mathbf{1 0 0}$ \\
\hline
\end{tabular}

For neonatal outcome, apgar score was used. Neonate apgar score at $2 \mathrm{~min}$ and $5 \mathrm{mins}$ were recorded. Apgar scores of $<7$ in 5 mins was considered significant. With regard to neonatal complications, low apgars were noted more with cerviprime group compared to the misoprostol group where only one neonate had severe birth asphyxia requiring NICU admission. There were no neonatal deaths (Table 11).

\section{DISCUSSION}

Elective induction of labour has become more common with patients presenting with risk factors and unfavorable cervix and when the benefits to either mother or foetus outweigh those of pregnancy continuation. Use of prostaglandins will often result in cervical ripening, softening and opening the cervix followed by labour induction.

This study was a prospective study over a duration of 15 months. The main aim was to study the efficacy and safety of the use of oral Tab. misoprostol as compared to intracervical cerviprime gel in the induction of labour using titrated low dose as per recommendations given by FIGO 2017. Most of the studies in the literature have compared the use of vaginal or sublingual misoprostol with that of cerviprime gel.
A total 159 cases with singleton pregnancy with cephalic presentation at term with a poor bishop's score and with intact membranes were enrolled in the study. After taking their consent they were randomly assigned to the cerviprime group and misoprostol group.

The gestational age of the patient varied from 37 weeks to 41 weeks which is similar to other studies. ${ }^{6-8}$ The mean gestational age for induction of labour were comparable between the two groups. The mean gestational age in the cerviprime group was 40 weeks 03 days and 39 weeks 06 days.

Postdatism was the main indication for elective induction of labour as found in other studies too. ${ }^{9-13}$ In our study postdatism was present in $71.05 \%$ and oligohydramnios in $9.21 \%$ of women in the cerviprime group. In the misoprostol group $42 \%$ were cases of postdatism and $14 \%$ were cases of pregnancy induced hypertension. Other indications included intrahepatic cholestasis of pregnancy, gestational diabetes and decreased foetal movements.

In this study, the difference in time duration from induction to delivery interval was significant and much longer in the misoprostol group than the cerviprime group, 25 hours 19 mins versus 19 hours 31 mins. The 
study done by Rathinamala et al and Langenegger EJ et al, also had the same findings. ${ }^{8,14,15}$

However, the mean duration of labour was similar in both the groups among the multis and the primis similar to another study by Patil $\mathrm{K}$ et al. ${ }^{10}$

There was no significant difference between oral misoprostol and intracervical dinoprostone in respect of the number of vaginal deliveries, similar to that in other studies. $^{15,16-19}$ In this study 70 women had vaginal delivery in the cerviprime group as compared to 73 women in the misoprostol group. However, all the instrumental deliveries were in the misoprostol group.

Even though the caesarean rates were higher in the cerviprime group $7.89 \%$ versus that in the misoprostol group $(4.81 \%)$, the caesarean rates were not very significantly different. The same findings were endorsed by Langenegger EJ et al. ${ }^{8,15,20,21}$ It was also noted that most caesareans were done for fetal distress and that was more in the cerviprime group. Wang $X$ et al, also noted the same finding in his study. ${ }^{17}$ However more women in the misoprostol group underwent caesarean for failed induction similar to a study by Patil K et al study. ${ }^{10}$

More women required augmentation with oxytocin in the cerviprime group (53.85\%) as compared to the misoprostol group $(46.15 \%)$ which was similar to other studies. $^{21-23}$

We also compared the frequency of maternal adverse events between groups, the overall incidence of uterine hyperstimulation, was very less and only one patient had this event in the misoprostol group. The proportion of maternal adverse events including fever with chills $(2.43 \%)$, GI symptoms $(3.65 \%)$ were more with the misoprostol group similar to that seen in the study by Wang $\mathrm{X}$ et al. ${ }^{8}$ For neonatal outcome, apgar score was used. Apgar scores of $<7$ in 5 mins was considered significant. With regard to neonatal complications low apgars were noted more with cerviprime group compared to the misoprostol group where only one neonate had severe birth asphyxia requiring NICU admission. The findings were similar in other studies. ${ }^{8,24}$

On calculating the total cost of induction per dose used it was found that the cost of induction with misoprostol was much cheaper than using cerviprime gel inspite of lesser number of doses in the cerviprime group. In primigravidae, it was amounting to around Rs 547.56 (Rs 253.50 per dose) as compared to mean dose of 10.17 with misoprostol amounting to Rs 63.56 (Rs 25 per 04 tablets). In multigravidae, the mean dose of cerviprime was 1.47 (Rs 372.64) versus mean dose of 7.50 (Rs 46.87) in the misoprostol group. As there was no significant difference in the maternal and neonatal morbidity, after weighing all the possibilities of risks and with proper consent misoprostol still may be considered as a possible method of induction.

\section{CONCLUSION}

It was found that cerviprime was more efficacious than misoprostol in induction of labour with a shorter induction to delivery time. However, there was no significant difference in the maternal and foetal complications. The caesarean rates were also comparable. Thus, though misoprostol shows promise as an inexpensive and convenient agent for labour induction, lower dose misoprostol regimens needs be investigated further. As the cost of treatment with misoprostol is much lower than that of cerviprime it may be used in low resource settings after taking into account all the possible contraindications to its use.

Funding: No funding sources

Conflict of interest: None declared

Ethical approval: The study was approved by the Institutional Ethics Committee

\section{REFERENCES}

1. World Health Organization. WHO Recommendations for Induction of Labour. Geneva: World Health Organization; 2011. Available at: http://apps.who.int/iris/bitstream/10665/44531/1/978 9241501156_eng.pdf.

2. Beischer NA, Mackay EV, Colditz PB. Obstetrics and the Newborn. An Illustrated Textbook; 1997;3:449.

3. Acharya T, Devkota R, Bhattarai B, Acharya R. Outcome of misoprostol and oxytocin in induction of labour. SAGE Open Med. 2017;5:1-7.

4. Goldberg AB, Greenberg MB, Darney PD. Misoprostol and pregnancy. $N$ Engl $J$ Med. 2001;344(1):38-48.

5. Morris JL, Winikoff B, Dabash R, Weeks A, Faundes A, Gemzell-Danielsson K. IJOG FIGO's updated recommendations for misoprostol used alone in gynecology and obstetrics, 2017. Available at: https://doi.org/10.1002/ijgo.12181.

6. Heffner LJ, Elkin E and Fretts RC. Impact of labor induction, gestational age, and maternal age on cesarean delivery rates. Obstet Gynecol. 2003;102(2):287-93.

7. Dongol A, Shakya S, Chawla C. Safety and efficacy of misoprostol for induction of labour. J Nepal Health Res Counc. 2010;8(1):27-30.

8. Wang X, Yang A, Ma Q, Li X, Qin L, He T. Comparative study of titrated oral misoprostol solution and vaginal dinoprostone for labor induction at term pregnancy. Arch Obstet Gynaecol. 2016;294(3):495-503.

9. Sahu L, Chakravertty B. Comparison of prostaglandin E1 (misoprostol) with prostaglandin E2(dinoprostone) for labor induction. J Obstet Gynecol India. 2004;54(2):139-42.

10. Patil K, Swamy MK, Rao RK. Oral misoprostol versus intra-cervical dinoprostone for cervical 
ripening and labour induction. J Obstet Gynec India. 2005;55(2):128-31.

11. Krishnamurthy MB, Srikantaiah AM. Misoprostol alone versus a combination of Dinoprostone and Oxytocin for induction of labour. J Obstet Gynec India. 2006;56(5):413-6.

12. Prager M, Eneroth-Grimfors E, Edlund M, Marions L. A randomised controlled trial of intravaginal dinoprostone, intravaginal misoprostol and transcervical balloon catheter for labour induction. BJOG. 2008;115(11):1443-50.

13. Yawn BP, Wollan P, McKeon K, Field CS.Temporal changes in rates and reasons for induction of term labor, 1980-1996. Am J Obstet Gynecol. 2001;184(4):611-9.

14. Balasubramaniyan RR, Sellathamby GD. Comparative study of cerviprime gel with oral misoprostol in induction of labour for post datism and PIH and IUGR. Indian J Applied Res. 2017;7:9.

15. Langenegger EJ, Odendaal HJ, Grové D. Clinical article oral misoprostol versus intracervical dinoprostone for induction of labor. International $\mathbf{J}$ Gynecol Obstet. 2005;88:242-8.

16. Windrim R, Bennet K, Mundle W, Young D. Oral administration of misoprostol for labour induction: a randomised controlled trial. Obstet Gynecol. 1997;89:392-7.

17. Dallenbach P, Boulvain M, Viardot C, Irion O. Oral misoprostol or vaginal dinoprostone for labour induction: a randomized controlled trial. Obstet Gynecol. 2003;188:162-7.

18. Hofmeyr GJ, Alferivic Z, Matonhodze B, Brocklehurst P, Campbell E, Nikodem VC. Titrated oral misoprostol solution for induction of labour: a multi-centre, randomised trial. Br J Obstet Gynaecol. 2001;108:952-9.

19. Barrilleaux PS, Bofill JA, Terrone DA, Magann EF, May WL, Morrison JC. Cervical ripening and induction of labour with misoprostol, dinoprostone gel, and a Foley catheter: a randomized trial of 3 techniques. Am J Obstet Gynecol. 2002;186:1124-9.

20. Alfirevic Z. Oral misoprostol for induction of labour. The cochrane database of systemic reviews. Ist Issue, Pub. John Wiley and Sons Ltd. 2006.

21. Kundodyiwa TW, Alfirevic Z, Weeks AD. Low-dose oral misoprostol for induction of labor: a systematic review. Obstet Gynecol. 2009;113(2 Pt 1):374.

22. Hofmeyr GJ, Gülmezoglu AM, Pileggi C. Vaginal misoprostol for cervical ripening and induction of labour. Cochrane Database Syst Rev. 2010;10:CD000941.

23. Bartha JL, Comino-Delgado R, Garci-Benasach F, Martinez-Del-Fresno P, Moreno-Corral LJ. Oral misoprostol and intracervical dinoprostone for cervical ripening and labor induction: a randomized comparison. Obstet Gynecol. 2000;96:465-9.

24. Faucett AM, Daniels K, Lee HC, El-Sayed YY, Blumenfeld YJ. Oral misoprostol versus vaginal dinoprostone for labor induction in nulliparous women at term. J Perinatol. 2014;34:95-9.

Cite this article as: Mukhopadhyay I, Sisodia D. Induction of labour at term: 25 mcg 2 hourly oral misoprostol or 6 hourly intracervical cerviprime, safety and efficacy. Int $\mathrm{J}$ Reprod Contracept Obstet Gynecol 2020;9:240-6. 